\title{
The Dilemma and Reform of Accounting Education in Colleges and Universities in the Internet + Era
}

\author{
Zhang Jun \\ Shaanxi Technical College of Finance and Economics, Shaanxi, China, 712000
}

Keywords: Internet; Colleges and Universities; Accounting Education

\begin{abstract}
Internet +" brings innovation and challenge to accounting education nowadays. Accounting educators in Colleges and universities should grasp the pulse of the development of "Internet +" in a timely manner, constantly push forward the concept innovation, goal optimization and mode transformation of traditional accounting education, and actively comply with the development trend of the accounting education era. Starting from the current situation and Prospect of accounting education theory in Colleges and universities, this paper analyzes the influence of "Internet + " on Accounting Education in Colleges and universities. Secondly, it discusses the realistic predicament of "Internet + " accounting education. On this basis, it studies the ways of transformation of accounting education in "Internet + " universities, with a view to further promoting the development of accounting education theory in China.
\end{abstract}

In December 2015, the Second World Internet Congress was held in Zhengzhou. During the "13th Five-Year year" period, President Xi proposed in Beijing that China will vigorously implement the "Internet +" action plan to effectively manage the Internet. In the future, "Internet +" will permeate people's learning, life, work and other fields. From the current point of view, the challenge of "Internet + " to traditional accounting education is beginning to show. The reform of accounting education in Colleges and universities is imperative. The so-called accounting education refers to the training of the educated in accounting thought, accounting behavior, accounting work and accounting innovation through the teaching of basic accounting theory, basic skills and basic methods. Its core content includes educational idea, educational goal and training mode. In the era of "Internet +", the traditional accounting education process exposes many disadvantages. Based on the characteristics of Internet and information management, a new accounting education mode which combines cloud computing, big data, Internet of Things and other intelligent technologies requires undergraduate accounting educators to strengthen the construction of new accounting education mode. Only this way can accounting education conform to the trend of the times and enable the learners of accounting education in Colleges and universities to truly grow up. Therefore, accounting education learners become applied talents with innovative spirit and international vision.

\section{The Difficulties Faced By Traditional Accounting Education Model}

As shown in figure 1, a detailed analysis is presented below. 


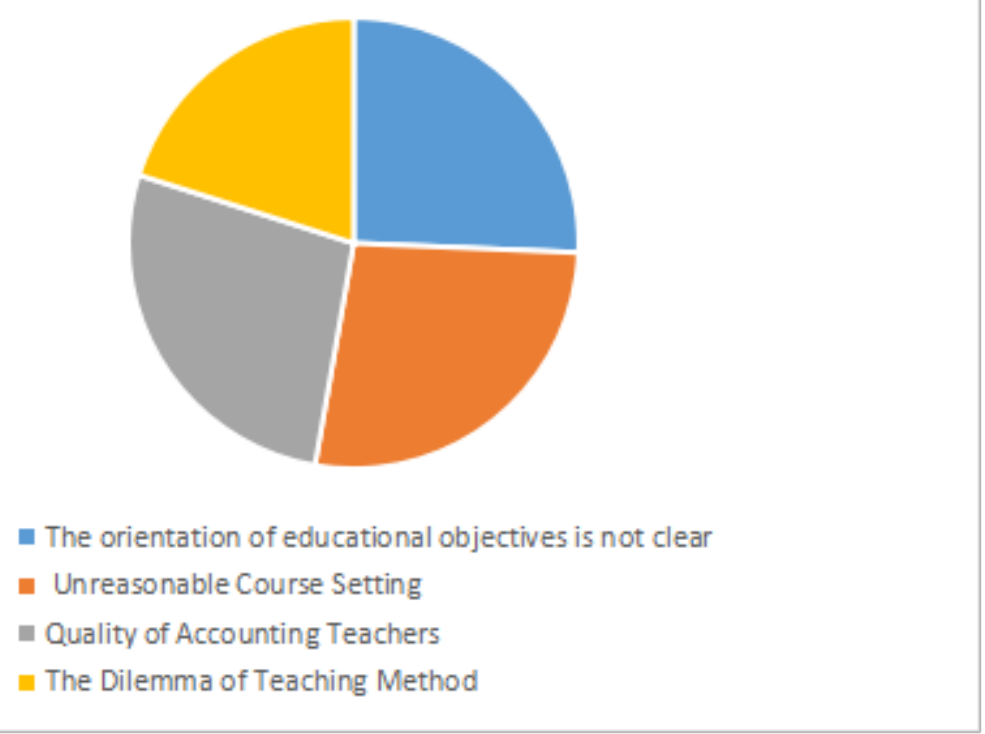

Figure 1.The Difficulties Faced by Traditional Accounting Education Model

\subsection{The Orientation of Educational Objectives is Not Clear}

Traditional accounting education and teaching starts with the basic accounting equation and uses the basic theory progressive method to upgrade the score theory to the middle and advanced level. But the improvement of theoretical level does not mean the improvement of ability level. Although training accounting talents is the purpose of accounting education, whether it can really meet the needs of the market remains to be verified. There are many colleges and universities at different levels throughout the country, ranging from vocational schools, higher vocational colleges to undergraduate courses, and then to master of accounting. From the point of view of training objectives, there are two main characteristics: one is to train "comprehensive talents", that is the combination of good academics of accounting theory and strong practitioners. Second, the target position is inconsistent. Undergraduate and higher vocational education have different training orientations for accounting professionals.

\subsection{Unreasonable Course Setting}

The shortcomings of traditional accounting teaching curriculum are increasingly apparent. Currently, the common curriculum system in Colleges and universities mostly adopts the implementation mode of ore-setting and fixed implementation. This curriculum mode setting may cause students to fail to make a reasonable connection between traditional knowledge and knowledge expansion in the new era of the Internet environment due to the untimely updating of knowledge in the process of education. At the same time, the inherent curriculum system can not make timely adaptations and improvements to the training of professionals according to market changes. The content of accounting course is complicated and its structure is unreasonable. At present, the general accounting course mainly covers basic courses and specialized courses, among which accounting expertise accounts for a large proportion. There are many overlapping and repetitive courses, such as basic accounting and financial accounting, which have obvious overlap in the fields of accounting and statement preparation. This kind of course design will not only make students not interested in the course, but also publicize the subject according to the texts. 


\subsection{Quality of Accounting Teachers}

At present, there are also some problems that can not be ignored in the teaching staff of accounting education. One is the knowledge structure of accounting teachers. The knowledge structure system of accounting teachers in China is still deeply influenced by traditional accounting education knowledge, and knowledge updating is slow. Especially the older qualified teachers who have been working for a long time, they have formed the inherent teaching mode, even the inherent teaching knowledge plate in the long process of practicing. In the information age, knowledge updating is not enthusiastic, or learning is slow. Online financial management, online payment, online agent bookkeeping and so on in the Internet age need the skilled mastery of accounting talents. As a financial teacher who imparts knowledge, accounting teachers should improve the knowledge reserve and theoretical learning in this respect. Secondly, most of the accounting teachers in our country enter the teaching staff directly after graduation from the graduate students of accounting specialty. They may have rich professional knowledge, but their educational experience is good enough, so they can easily follow the old road of publicizing the subject according to the texts.

\subsection{THE Dilemma of Teaching Method}

The traditional teaching method is based on the classroom teaching mode. Teachers teach according to the texts, mechanical teaching, students in the clouds, passive acceptance. Accounting is a more practical subject. But the training mode still follows the traditional way. This is not conducive to the cultivation of uninteresting in accounting and the deep study of specific principles. In the long run, it has resulted in the embarrassing situation of studentship theory and poor practice. In the teaching organization, the carrier is the classroom teacher's teaching. Practice is based on superficial accounting knowledge, which requires less practice. Research and investigation are mainly based on the memory of accounting details, but the ability of accounting principles and analysis of the problems behind them is completely absent. This obsolete teaching mode has greatly reduced uninteresting in learning and learning efficiency, and is also disconnected from the growing knowledge economy today.

\section{Accounting Education Reform Strategy}

\section{Rational Definition of Accounting Education Objectives}

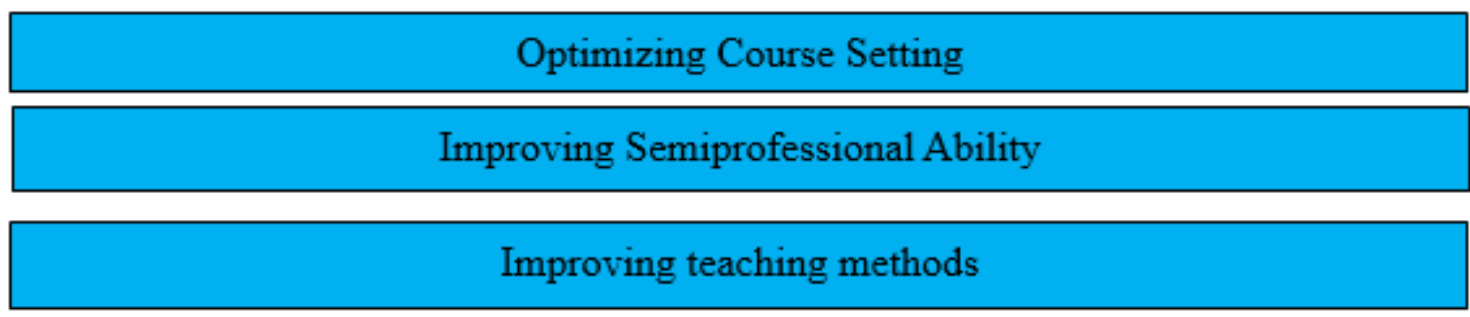

Figure 2. Accounting Education Reform Strategy

As shown in figure 2, a detailed analysis is presented below.

\subsection{Rational Definition of Accounting Education Objectives}

According to the economic development model in the new era and the characteristics of 
information explosion in the network era, we must define the educational objectives of accounting profession reasonably. The author believes that the goal of accounting education nowadays should be to help students think and diverge, as well as cultivate professional ethics. The training of accounting professionals should also pay more attention to denuclearizing ability rather than knowledge reserve. Learning ability is not only the learning of constantly updated new knowledge, but also the training of students' skills learning ability. It is hoped that students can face the new challenges of the Internet era and stand in the forest of social competition through self-learning after entering the society.

\subsection{Optimizing Course Setting}

Firstly, in the Internet era, the organic unity of accounting, law and management knowledge is more emphasized. Colleges and universities are required to set up corresponding courses to cope with the complex market environment, to help students understand the accounting environment and the impact of acclimatization on the accounting industry, and to improve their ability. Secondly, we should attach importance to the relative independence of the content of each course. Each course has its own professional characteristics which can not be replaced by other courses. While emphasizing the integration of various courses, it can not obliterate the necessity of the existence of each course. Professional knowledge still needs special mastery. Thirdly, we should pay attention to the cohesion of various subjects. Especially for specialized courses, the content of each subject should be flexible, and there is no uniform standard for its content division. It requires that all subjects should be able to arrange the curriculum system reasonably in accordance with the characteristics of the Internet era.

\subsection{Improving Semiprofessional Ability}

We should pay attention to the following aspects for the quality of accounting education teachers in Colleges and universities in the Internet era: first, we should strengthen the follow-up study and education of accounting teachers, emphasize their self-learning consciousness and ability, and pay attention to the new policies and laws issued by our country. The second is to learn computer and foreign language skills. In the Internet era, there are higher requirements for computer skills and foreign language skills of accounting talents. In addition, teachers should also have a certain ability to maintain conventional financial software, and be skilled in using various office software, which is the current financial personnel should have the skills. Thirdly, colleges and universities should call on teachers to take the examination of accounting profession type so as to improve the level of accounting theory knowledge and business application. Accounting teachers should be able to achieve the unity of knowledge and practice, both as deliminators of knowledge and as pilots of practice.

\subsection{Improving teaching methods}

One is the emergence of many new accounting learning modes in the Internet era, such as various learning software "micro-classroom, MOOC" and so on. Among them, the accounting knowledge classroom is rich in form and flexible in teaching, which can be used as a way of after-school learning for students. The second is to establish an inquiry-based teaching model, the Internet can be used as an efficient and convenient learning platform. We must encourage students to be good at finding problems, putting forward solutions, communicating with teachers in time, and improving studentship learning efficiency. Thirdly, network resource sharing database can be established among schools and University teachers. Communication between teaching and learning 
is very important. Exchange teaching experience in the form of database, discuss hot issues of disciplines, and improve the level of education and development of accounting professional knowledge.

\section{Conclusion}

The transformation of new accounting education mode in the era of "Internet + " is a long-term process, which requires strong team support and cannot be achieved overnight. This team should include not only accounting teachers, but also experts in computer, network, information technology and other disciplines. Of course, its advantages are obvious. It can break through the barriers of reality and space limitations, quickly store and process massive information data, instantly meet the large-scale interaction between teachers and students, and realize resource sharing. In March 2016, the National People's Congress formulated the "13th Five-Year plan" outline, and put forward the implementation of the "Internet + action plan", which greatly promoted the wide application of the Internet. Therefore, universities must pay close attention to the necessity and urgency of sharing big data accounting resources from the ideological level. Colleges and universities must actively explore, dare to innovate, and actively promote the rapid development of accounting education teaching content.

\section{References}

[1] Lean Fugue. On Accounting Education Concept [J]. Accounting Research, 2013 (4): 20-24.

[2] Li Kaifeng, Jingo Suzy. Literature Review of Accounting Education Research in China - Based on the Perspective of Comparative Research [J]. Accounting Research, 2015 (6): 80-87.

[3] Gong Ling. Reform and Practice of Accounting Education Teaching in the Internet and Big Data Era [J]. Knowledge Economy, 2016 (4): 116-118.

[4] Bhang Hongi. Challenge of Internet + to China's accounting education [J]. Management and technology of small and medium enterprises, 2015 (10): 232-233.

[5] Bhang Lin, Ding Bin, G Deng. Accounting reform and development in the era of "Internet +" -- a summary of the 2015 annual academic meeting of the Chinese Accounting Society [J]. Accounting research, 2015 (8): 9 